The presentation of self in scholarly life: identity and marginalization in academic homepages

Ken Hyland,

University of Hong Kong

Centre for Applied English Studies

$7^{\text {th }}$ Floor KK Leung Building

The University of Hong Kong

KK Leung Building

Pokfulam Road

Hong Kong

Email: khyland@hku.hk 


\title{
The presentation of self in scholarly life: identity and marginalization in academic homepages
}

\begin{abstract}
The academic homepage is now a ubiquitous genre of scholarly life, but despite considerable interest in issues of identity and the ways individuals self-consciously manage the impression they give of themselves, it has been slow to attract the attention of ESP researchers. This may be because of the institutional control exercised by employing universities over this genre which tends to marginalize its subjects. The personal homepages of academics, however, offer considerable insights into disciplinary communities and the construction of a public identity in the context of corporate branding. In this paper I explore 100 academic homepages in two contrasting fields, subdivided by rank and gender, to identify the extent of this marginalization and the space remaining to academics. Through an analysis of what is said and how it is presented, as text, design and hyperlinks, I show how individuals are positioned by corporate discourses yet manage to carve a sense of self to assert professional credibility. The analysis shows something of how language interacts with other semiotic resources in this environment and how seniority, gender and disciplinary membership cross-cut institutional representations of academics as employees.
\end{abstract}

\section{Keywords}

Homepages; identity; academic discourse; multimodal texts; corporate branding

\section{Bio}

Ken Hyland is Professor of Applied Linguistics and Director of the Centre for Applied English Studies at the University of Hong Kong. He has published over 150 articles and 14 books on language education and academic writing. He was founding co-editor of the Journal of English for Academic Purposes and is now co-editor of Applied Linguistics 


\section{Introduction}

The connection between writing and identity has been a subject of academic interest for some time (e.g. Ivanic, 1998). While issues of agency and conformity, stability and change, remain controversial, there is some agreement that identity is created from the texts we engage in and the linguistic choices we make, thus relocating it from hidden processes of cognition to its social construction in discourse (Benwell \& Stokoe, 2006). In academic contexts identity has often been seen as the ways that individuals work to reproduce or challenge dominant practices and discourses, often producing conflicts in academic and other ways of knowing (e.g. Lillis, 2001). The process of constructing an identity, however, most clearly involves selecting materials to present to others, a process of summation which might be seen most directly in personal homepages.

However, while creating a personal page encourages self-dialogue and reflection about how to create a public presentation of self, academic homepages often reveal the purposes of the university as much as the individual. Faculty members construct an identity online in the context of a university managed space and so reveal an individual supported by institutional infrastructures and linked into networks of colleagues, publications, interests, courses and students, all of which are carefully selected to assert both the professional credibility of the subject and the status of the employer. However, precisely what this selection comprises, the extent to which individual choice is eliminated by this process, and how far the construction of identity differs by seniority, gender and discipline remains unclear. I seek, therefore, to discover how academics use various semiotic resources to construct an identity online in the context of the university as a workplace. First I offer a brief sketch of this genre, its relationship to identity and its importance in academic life, then go on to explore the discursive construction of identity in 100 homepages of academics in two contrasting disciplines sub-divided by gender and rank.

\section{Online identities}

Following the pioneering work by Goffman (1971), there is now considerable interest in how 
individuals self-consciously manage the impression they give of themselves in different social contexts. Among these contexts, the homepage is recognized as an increasingly significant means of self-representation and as a result is fast becoming an object of academic study. Analyses have emerged, for example, into the homepages created by such diverse groups as adolescents (Stern, 2004), members of the House of Representatives (Adler et al, 1998), Fortune 500 companies (Liu, et al, 1997) and lonely Chinese seafarers (Tang, 2007).

The homepage owes its rapid rise, at least in part, to the fact that no other medium is better suited to fulfilling the present-day demands of identity work which seeks to balance the differentiation of modern life with the construction of coherence and meaning. The postmodern view of identity, understood as a patchwork (Kraus, 2000) or pastiche (Gergen, 1991) of independent and partially contradictory sub-identities, finds its expression in a medium which is always "under construction" and which can be regularly updated to reflect the latest self-conceptions. It is also a genre which facilitates the joining of diverse and diachronic self-aspects and sub-identities with links in its hypertext-structure (Chandler, 1998). Representing one's patchwork identity on a personal home page can therefore help foster the feeling of self-integration and self-effectiveness, but more than this, and at the same time, it is especially well suited for an elaborate strategic self-presentation (Chandler, 1998; Wynn \& Katz, 1997).

The homepage therefore allows analyst to capture a more authentic and meaningful projection of self than through what seems to have become the default methodology for researchers in recent years: the narrative interview. The interview is an autobiographical reconstruction which allows subjects to reconceptualise their actions as representing a coherently motivated picture of continuity and sameness. It reflects Giddens' (1991) view that self and reflexivity are interwoven, so that identity does not involve the possession of particular character traits, but the ability to construct a reflexive narrative of the self. These interviews thus emphasizes the subject's continual interpretation and reinterpretation of experience through a cultural lens, but because they focus on what people say about themselves in formal interviews with complete strangers, it is essentially a contrived, formal, 
anonymous and low-stakes genre. In contrast, the homepage reveals the same kinds of deliberately constructed identity claims but in a context where the elicitation is not the motive for the telling. It allows us to see such claims in a context which has the potential for a genuine projection of self.

Drawing on various modalities, with an attractive, information-rich presentation, homepage authors can strategically manage the impression they make on people who have never met them. For Parks \& Archey -Ladas (2003: 4), then, the homepage provides 'an incredibly flexible and unencumbered stage for the construction of identity'. Chandler (1998), in fact, believes the medium offers possibilities both for the presentation and shaping of self which are shared neither by paper texts or by face-to-face interaction. As he observes:

On the Web, the personal function of 'discovering' (or at least clarifying) one's thoughts, feelings and identity is fused with the public function of publishing these to a larger audience than traditional media have ever offered. (Chandler, 1998:10). The psychological need for cognitive integration is therefore married to the sociciological need for self-representation and group membership. Personal home pages convey an impression of how one would like to be seen by others, thus offering opportunities for contacts and networking (Chandler \& Roberts-Young, 1998) and also for the kind of public relations work which can help create a certain collective identity (Hyland, 2011).

The personal home page therefore supplements our means of impression management through interpersonal and public relations communication, supplemented by new ways of signifying meaning such as hyperlinks to show social connections and images to project visual presentations of the self. When online, moreover, we inevitably draw on previous social knowledge of how to present ourselves, so that many of these representations involve similar conventions to those found in offline spaces. In personal homepages all these linguistic, content and design features are typically under authors' control, allowing them to construct representations which will be recognized and valued by significant others and so revealing something of how they understand their communities. When located in a university context, however, the situation is less clear. 


\section{The academic homepage}

The homepage is now firmly established as an ubiquitous feature of scholarly life. A recent study of the social networking practices of over half a million academics, for example, found that $71 \%$ of the researchers had at least one homepage (Tang et al, 2007). It is a genre of interest to a range of groups seeking information about individual scholars, not least researchers, students, conference organizers, editors, publishers, university administrators, and recruitment head-hunters. It has therefore become almost obligatory for academics to maintain some kind of online presence. It is equally true, however, that universities themselves are alert to the value of these homepages to themselves: in offering online resources for students, displaying credentials of the scholars who comprise their faculty, and functioning to advertise and promote departments, courses, and the individual instructor. As Hess (2002: 172) observes, 'As a faculty member designs her homepage, it becomes an advertisement for the faculty member, yet it is also an advertisement for the department and university'.

So while part of the allure of maintaining a homepage is to control one's representation of self online, the fact that it is located on a university server and accessed through a university website means that it can act as a means of institutional governance. From a Foucauldian perspective, of course, this is not surprising. In Foucault's (1972) account, identities are regarded as the product of dominant discourses tied to social arrangements, so that identity is inscribed in powerful discourses which shape and direct the individual. When we look at academic homepages in this way, we might see them as products of university design teams which machine them to conform to current models of university commercialism. So, Thoms and Thelwall (2005), for example, argue that academics relinquish their power to the university for reconstructing the self as the institution seeks to legitimate its own credibility and attract ever more resources.

Creating this identity involves what Chandler and Roberts-Young (1998) call bricolage, where the author doesn't so much write, but assembles the culturally valued attributes of his or her trade: the 
set of symbolic resources from which identity is constructed for public approval. In academic homepages, it is clear that the inclusion, omission, adaptation and arrangement of elements is not entirely under the author's control, so that the author is often not the owner of the page and his or her identity claim is incorporated into the symbolic eminence of the institution. What is a platform for global visibility and a declaration of academic credibility, therefore, is appropriated into the representation of the institution itself which claims ownership over the expertise of its employees. The individual, immersed in the institutional paraphernalia of research groups, publications and students which comprises the public persona of an academic, is simultaneously constructed in terms of the university's electronic shop window.

The extent to which academics are denied any autonomous subjectivity in the construction of their online identities is, however, uncertain. There have been only a handful of studies which have addressed the construction of academic identities on the web (e.g. Hess, 2002; Thoms \& Thelwell, 2005 ) and these have largely focused on simple analyses of content (Dumony \& Frindte, 2005) or power relations (Thoms \& Thelwall, 2005). These suggest that academics tend to offer a 'focal-self' (Miller, 1995) which emphasizes an academic identity and the expense of more personal aspects of the self. Dumont and Frindte (2005), for example, found that information about research activities dominated the contents of psychologists' homepages, while women's pages, in particular, appear to conform to institutional representations and focus more on their credentials as academics (Hess, 2002; Arnold \& Miller, 2001). This study seeks to show the ways faculty members construct their online identity in a university managed space and to reveal something of how these homepages are mediated and shaped by social factors.

\section{Data and method}

I studied 100 academic homepages with 50 each from philosophy and physics, representing a crosssection of practice from the humanities and hard sciences respectively and email interviewed five webpage subjects from each. To ensure some institutional standardization, I selected pages from universities in the top 25 of the QS-Times Higher world University rankings for $2009^{\mathrm{i}}$. The QS-THS 
listings rank over 600 universities based on six indicators: the proportion of international students and staff, citations per faculty, staff-student ratio and employer views, but weighted heavily (40\%) towards an opinion survey of 10,000 academics world- wide. It was thought that this list would provide a broad international base of comparable institutions from which to collect data for the study. This selection was then stratified according to rank and gender, with 25 full professors and 25 Assistant Professors and 25 men and 25 women from each discipline. The authors were affiliated with institutions in over 10 countries.

The decision to identify the authors by their academic status and gender was, like the categorisation of the corpus by discipline, based on assumptions about the possible significance of these factors in mediating a self representation and perhaps challenging institutional representations. My hypothesis was that the ways writers present themselves might be influenced by their experiences in their profession as women or men and by their seniority.

I then analysed the homepages looking at their texts, visual design and hyperlinks. I used NVivo 8, a qualitative software programme, to code the text by what was mentioned. The position, size and content of photographs were also recorded and the hypertext links were followed and categorised. The content writers included was considered in terms of how it was structured as rhetorical units, each unit seen as a distinctive communicative act projecting a particular aspect of the self. After several passes through the corpus, I settled on this coding scheme which embraced all the data:

- Achievements \& awards

- Community Service

- Education background
- Employment

- Personal details

- Publications \& conferences
- Research interests

- Teaching

- Contact details

These categories provide some detail for those searching for the person behind the conference presentation, academic article, or course description, but they reveal that representations were largely restricted to an academic identity. I followed this up with email interviews with randomly selected academics from the corpus to explore choices further and to better understand the extent of agency 
available to individuals. In what follows I discuss what is said about the self and how it is presented as text, design and through hyperlinks. In this way I hope to draw these threads of authorship and identity together.

\section{Text choices in the academic homepage}

The interviews offer some insights into agency in this genre and confirm that options are often restricted by institutional design. While only one of my, admittedly small, sample of respondents mentioned having to 'write to a template', academics often felt constrained in creating their profiles by space or the attentions of department webmasters. These comments are typical:

We are given guidelines about what we should include and word limits for how much we should write. I'm not sure how strict these are, but they just relate to publications and what topics we can supervise.

(Philosopher)

I guess it is important to present a common front as it makes the department look slick and professional. That kind of thing seems to be important these days. (Physicist)

These constraints perhaps help account for the general uniformity in content choices shown in Table 1, which gives the percentages of individuals who included each identity move in their homepage.

Table 1: Move frequencies by social characteristics (\% of all academics)

\begin{tabular}{|c|c|c|c|c|c|c|c|c|c|}
\hline Moves & Contact & Education & Employment & Personal & Research & Publications & Teaching & Award & Service \\
\hline Overall & 84 & 62 & 96 & 14 & 91 & 68 & 34 & 14 & 12 \\
\hline Professors & 82 & 52 & 96 & 17 & 92 & 80 & 39 & 17 & 20 \\
\hline Assist Prof & 86 & 70 & 96 & 7 & 90 & 54 & 27 & 7 & 4 \\
\hline Male & 82 & 61 & 96 & 16 & 91 & 60 & 35 & 9 & 11 \\
\hline Female & 87 & 60 & 97 & 6 & 91 & 76 & 31 & 16 & 13 \\
\hline Physicists & 72 & 57 & 92 & 11 & 90 & 57 & 26 & 21 & 10 \\
\hline Philosophers & 96 & 69 & 100 & 19 & 93 & 79 & 43 & 6 & 14 \\
\hline
\end{tabular}

Employment was the highest frequency move with all but a handful of physicists stating their current and past positions. Together with a statement of research interests, this comprised a substantial portion of the text of the corpus. Employment histories and research concerns are clearly the staples 
of the curriculum vitae and are available to everyone from the Nobel Professor to the lowly lab rat and so find their way into most constructions of the academic self. This information was generally accompanied by an email address, telephone number and office address, details which invite interaction and provide opportunities for readers to cross-check the given information (Parks \& Archey-Ladas, 2003). The figures are unsurprising in that employment credentials and research interests promote both the individual and the institution, linking the academic into a network of credible associations and advertising the university to potential graduate students and employees.

Less frequent than expected in this corpus, perhaps, are moves which relate to the author's research and teaching. In only two thirds of the homepages studied did author's mention their publication output and just a third referred to their teaching and supervision on their main page. Clearly there is more going on here than academics simply following instructions to legitimate the authority of their employers. In fact, decisions about what to include are not entirely determined by university marketing objectives but are negotiated with individuals, as these respondents confirmed:

I gave them some info for the webpage but didn't fill in all their boxes. I thought some information was more important about who I was and how I saw myself as an academic. It was more important to include it than some of the other things they wanted.

I've published a lot in the last couple of years as we had a major project come to an end and I wanted to highlight that on my page. Nobody seemed to mind that I left out the courses I was teaching.

(Physicist)

An important mediating factor in the ways academics portray themselves online seems to be the status of the author, with assistant professors falling back on their qualifications and education in the absence of the publication and teaching records of their senior colleagues. For many writers, however, they used the opportunity to locate themselves in the academic milieu through association with a particular institution and individuals (1) and by stating their research interests (2):

(1) I got my PhD from the Philosophy Department at UC Berkeley in 2003; my advisors were Richard Wollheim, John Searle, and John MacFarlane. 
I did my Ph.D. at Caltech from 1999 to 2003 at Caltech, under the supervision of Prof. Kip S. Thorne. I graduated from Peking University (China) in 1999; my thesis advisor was Prof. Tan-sheng Cheng (I also did some research under Prof. Zheng-xiang Gao).

(2) I currently work on problems related to (or motivated by) the effort to detect gravitational waves.

Areas of Specialization: Ethics; Philosophy of Action; Philosophy of Mind; Philosophy of the Social Sciences

Specialist interests represent a key way of establishing a claim to expertise and professional credibility for all academics, but senior scholars have a greater repertoire of experiences to draw on in constructing their online identity and so were able to include far more on publications, teaching, awards and service.

Gender is a less significant influence on this data. As with other academic genres such as book reviews (Tse \& Hyland, 2009) and bio statements (Hyland \& Tse, forthcoming), the choices made by males and females is broadly similar. But while the actual frequencies are not large, there are small differences in that females were more likely to mention their publications ( $21 \%$ more moves) and awards (43\%), and males to give more personal information (45\%). Both groups mentioned their research interests, but females, especially those in philosophy, were largely alone in specifying particular titles, often with a summary for non-specialists, as in this example:

(3) She is the author of four books. The Sources of Normativity (Cambridge 1996), an expanded version of her 1992 Tanner Lectures, examines the history of ideas about the foundations of obligation in modern moral philosophy and presents an account of her own. Creating the Kingdom of Ends (Cambridge 1996) is a collection of her essays on Kant's Ethics and Kantian Ethics. The Constitution of Agency (forthcoming Oxford fall 2008), is a collection of her recent papers on practical reason and moral psychology. And SelfConstitution: Agency, Identity, and Integrity (2009) is a book about the foundation of morality in the nature of agency.

The most obvious potential indicator of institutional control over the ways these academics 
represented themselves online is the overwhelming predominance of professionally related information. Individuals, however, found space to develop a more multifaceted subjectivity by including information on hobbies, interests, family and so on which reaches beyond the trappings of academic life. Two academics commented on this:

I wanted to put up something a bit more personal - what I like to read and the music I listen too. I didn't want to be seen as just a one-dimensional swot.

(Philosopher)

The brief from the department said we should include our research and publications and so on, but didn't say anything about what we couldn't put up. Of course most of what is there is going to be about our professional activities, after all, it is a university site, but there is more to life than that. I added some links to my favourite places.

(Physicist)

So at least some subjects sought to convey a more personal self among the academic identity constructs of the genre. Males, and especially senior males, tended to present this aspect of themselves rather more than females (links underlined):

(4) In the summer of 2007 my wife and I cycled the length of Great Britain (Land's End to John O'Groats). Here are descriptions and pictures of the trip. (Physics professor)

* New house in San Francisco $*$ Painting * Sailing * Wooden boat modelling

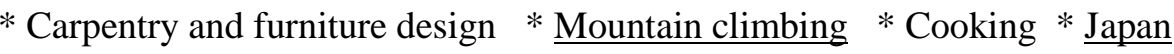

(Philosophy professor)

Whether this more personal aspect of the self is deliberately suppressed by university marketing ideologies is a moot point as we also find this reluctance to convey personal information in the selfcreated personal homepages of these authors. This suggests that relative avoidance of non-academic subjectivities may, at least in part, be a deliberate choice rather than the effect of institutional branding.

Where activities outside academia were included, however, it was once again men who were more likely to reveal information about their personal lives. It is unclear why this is, although Tannen 
(1990) might suggest that it has something to do with males predilection for collecting, listing and imparting facts:

(5) I really enjoy music. My favorite genres tend to be progressive metal (e.g. Mastodon, $\underline{\text { Isis) }}$ and progressive rock (e.g. Yes, King Crimson), but many of the artists I like do not fit into either of these categories (e.g. John Coltrane, Allan Holdsworth, and Steve

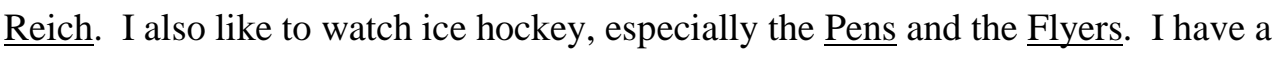
great appreciation for the beers of the Chouffland.

Outside the Department, I enjoy the complete suite of dweeb passtimes: listening to The Archers, bird watching, politely refusing alcoholic beverages. Unfortunately, having been born too late for The Age of Steam, I never developed into trainspotting. My favourite things include: hamsters , Rocky Mountain National Park, Here and There in The Observatory magazine.

The mention of "dweeb pastimes" in the second example is a tongue in cheek acknowledgement of this tendency, perhaps; a self-deprecating reference to a rather over-studious and perhaps socially inept individual, but the inclusion of these interests offers a picture of a more complex and rounded character than that found on the university homepage.

The biggest impact on homepage content appears to be discipline, with Philosophers making greater use of moves in most categories except awards. Physicists were far less likely to post details of their teaching and publication outputs, and often simply listed a few recent references or a hyperlink without comment. The philosophers, on the other hand, generally provided a commentary on the book and a sketch of its argument or impact:

(6) Professor Pereboom works in free will and moral responsibility, philosophy of mind, history of modern philosophy, and philosophy of religion, and has published articles in each of these areas. In his book on free will and moral responsibility, Living Without Free Will, he argues that we human beings do not have the sort of free will required for praiseworthiness and blameworthiness, but conceiving ourselves as lacking this sort of free will this does not undermine what is important for morality and meaning in life.

Even where frequencies are similar in the two fields, moves are often expressed differently. Writers in both disciplines had a lot to say about their research interests, for example, but philosophers usually 
expressed this in the first person:

(7) My research focuses on the medical and life sciences as they existed from the early sixteenth-century to the beginnings of the nineteenth-century. With an emphasis on historical accuracy, I try to provide philosophical accounts of the ideas and arguments of past thinkers as they understood their predecessors and attempted their own experimental and theoretical innovations.

I am mainly interested in how scientific method could possibly lead us to true generalizations about Nature; generalizations that extend infinitely beyond our current, finite perspective.

Physicists, on the other hand, tended to employ the third person and refer to their lab membership as a way of presenting their interests and establishing their research credentials. Membership of a prestigious work group can imply status by association at the same time as it informs readers of one's professional commitments. Interestingly, these descriptions are often written for a non-specialist audience, speaking to a wider scientific community than the webpage author's particular field:

(8) The broad focus of Prof. Baranger's group is the interplay of electron-electron interactions and quantum interference at the nanoscale. Fundamental interest in nanophysics -the physics of small, nanometer scale, bits of solid - stems from the ability to control and probe systems on length scales larger than atoms but small enough that the averaging inherent in bulk properties has not yet occurred. Using this ability, entirely unanticipated phenomena can be uncovered on the one hand, and the microscopic basis of bulk phenomena can be probed on the other.

Her research program on galaxy formation and evolution complements the Penn astrophysics research program, whose main focus is on issues related to dark matter and dark energy. Her research will benefit from Penn's membership in the DarkEnergy Survey (DES) and the Large-Scale Synoptic Telescope (LSST).

A description of the writer's interest therefore both advances the expertise and competence of the homepage owner as well as promote the specialism and the research group to prospective graduate students and other academics.

In short, while university ideologies undoubtedly exert control over what writers include in their pages, this is not the full story. In particular, we can see in these distinctive representations how 
disciplinary activity can encourages the performance of different kinds of professional identities. Here there are different orientations to community and epistemology. The philosophers tend to characterize themselves in terms of the more individualistic ethos of a discipline which sees interpretations and arguments as the creative insights of the author, while the physicists position themselves as players in a domain where results are the collective endeavours of a team. Here knowledge is shared and part of a cooperative context rather than personally owned.

\section{Formatting and images}

University governance is most striking in the visual design of academic homepages. The aesthetics of websites contribute not only to their attractiveness, but also to their effectiveness in how long users stay and what they remember later (Bonnardel, Piolat \& Le Bigot, 2010). But more than this, they contribute to the way the subject is positioned. The importance of design cannot be overestimated as online texts are never purely linguistic but involve different semiotic resources which, in combination, create new meanings. For Kress (2010) and other theorists, the screen is organized by the logic of image, not text, which orders the various 'systems of meanings' that are found there, so that the visual does not just superficially embellish text, but plays a central semiotic role (Jewitt, 2005). Unlike the D-I-Y feel of many personal pages then, the glossy, polished product which greets the visitor to an academic site represents academics in a very different way as text is integrated with images, page layout, colour, and hyperlinks.

Page formatting and colour, however, are almost always determined by the employing institution. University and department names and logos tend to dominate academic homepages with banner text along the top, departmental links down the side and webmaster information along the bottom. The repetition of these features across the homepages of all the members of a department have been seen as symbols of ownership which help position the individual as an employee (Thoms \& Thelwell, 2005). While this largely serves the corporate interests of the employing institution, it also squeezes the space available for the individual to represent themselves without requiring further work by the viewer to link to other screens. The two homepages reproduced as Figs 1 and 2 are typical of this. 
Figure 1: Philosopher's homepage at John Hopkins University

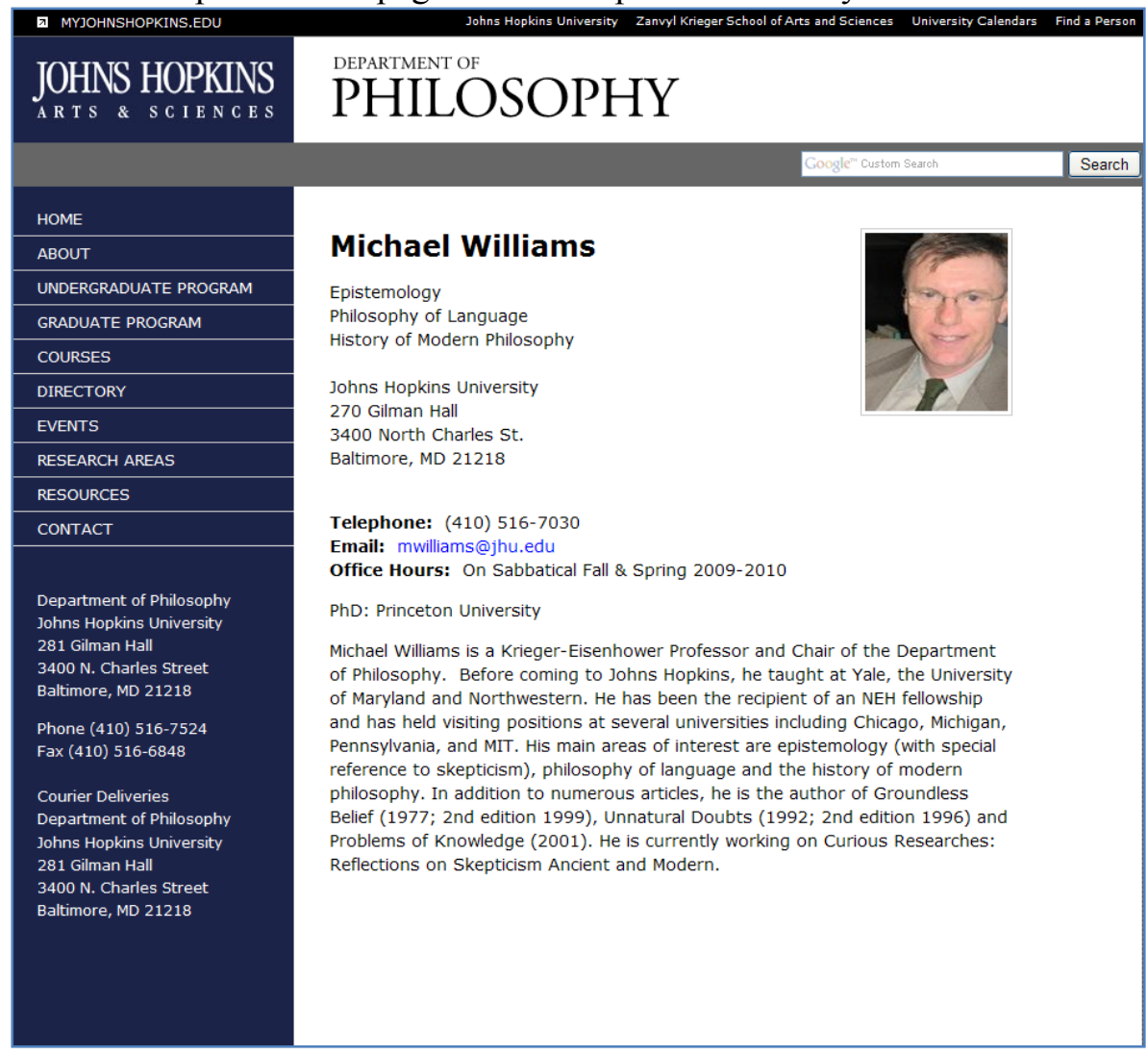

Figure 2: Physicist's homepage at University of Michigan

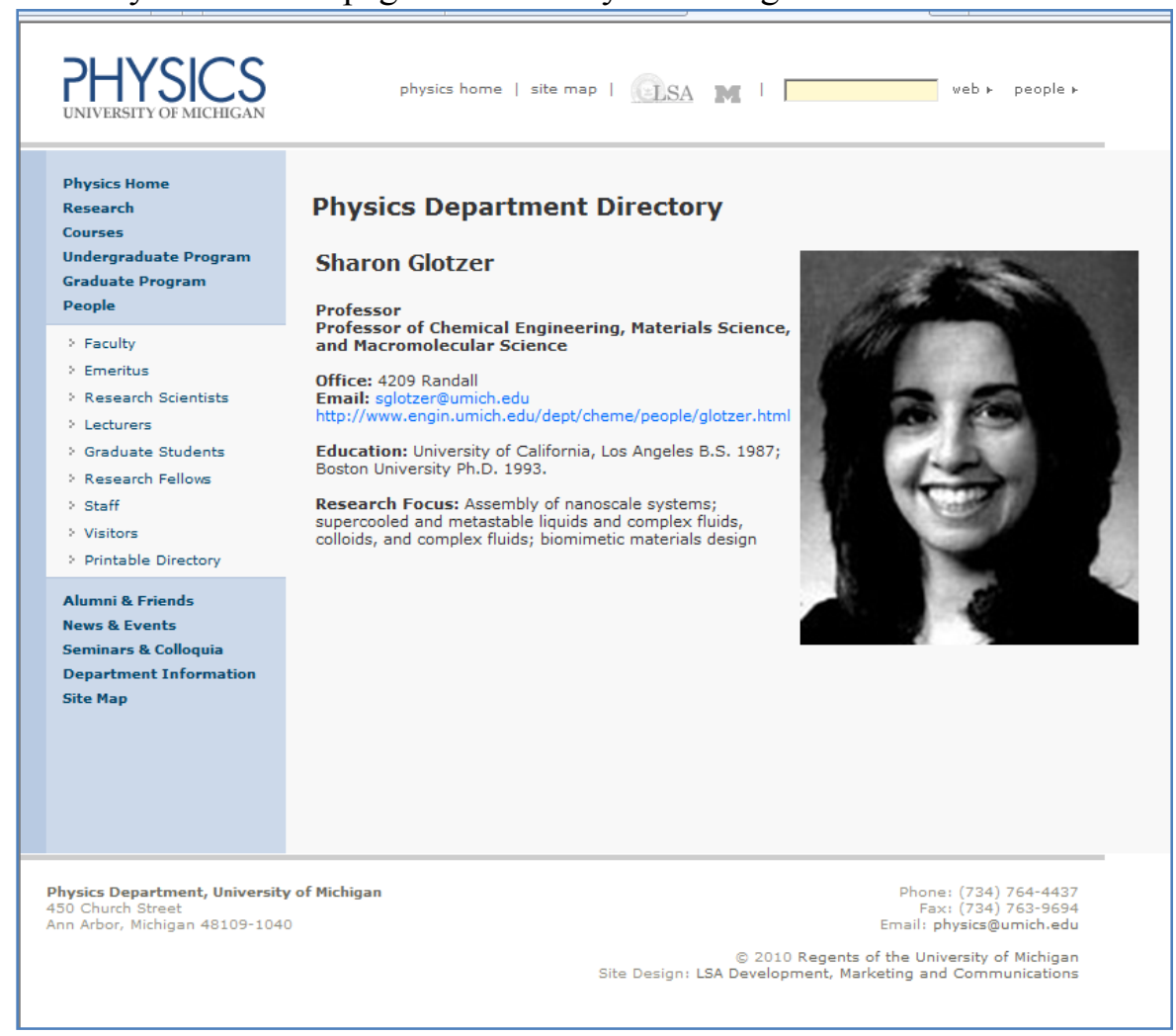


While located in different disciplines, departments and universities, these homepages share a uniform appearance. The pages have a compositional unity deriving from a horizontal and vertical-grid structure, and this unity is reinforced by the choice of two main colours, sidebars and banners. The pages are dominated by banners proclaiming the respective departments and universities of the two academics, with the area available to the individual restricted to a third of the screen. In the space remaining, the subjects construct themselves through a brief paragraph, contact details, and a photograph.

Homepage screens ask the reader to perform different semiotic work than page-based texts, offering different entry points and different reading paths from the order of words in a sentence, but this does not mean that the ways we 'read' image-based texts is entirely unconstrained. For multi-modal semioticians, the placement of elements is significant, so that putting something above others can signify superiority or importance, for example. In these texts, the department banner is clearly given prominence at the top of the page and following convention, the reader assumes the text on the left, providing access to information on departmental and institutional matters, is intended to be scanned first. While reading paths are relatively open in images compared to texts, the left-side text is also given prominence through being set in a contrastive saturated darker colour and shape.

We do, however, distinguish headers and sidebars from main text. Following Kress and van Leeuwen's analogy with written texts, it is what occurs on the right which is regarded as the viewer as key information. The right side is where the reader must pay particular attention to find the 'message' while the left is 'already given', or what the reader may be assumed to 'know already' as part of the context. The institutional links are presented as a familiar and agreed upon point of departure for what is not yet known: the representation of the homepage subject. Compared with the relatively dense lists on the left of the screens, the uncluttered white space available to the academics themselves draws the eye to the subjects' information and, in particular, their photographs. In so doing it facilitates and supports an alternative pathway: the modern world's preference for image in 
online domains. The photos, in fact, are quite salient in this space and therefore demand attention, inviting viewers to form a positive identification of the academic.

All but a dozen homepages in the corpus contained a photo of the author. These were positioned alongside the written text and almost always towards the top of the page, on the right, and were always of the subject alone, irrespective of discipline, gender or rank. While photographs allow viewers another way of understanding the subject and an opportunity to scrutinize what the 'carrier's possessive attributes' (Kress \& van Leuwen, 1996), or parts of the whole, most gave little away. Many were obviously taken by in-house photographers and over two thirds were a tightly cropped portrait with no articulated background, betraying little context and so reducing our ability to see the individual as anything more than a generic academic filing a vacant place on the homepage. This absence of setting not only reduces personal information about the subject, but disconnects him or her from time and place. Where a background could be discerned it was likely to be an office, although $25 \%$ of all authors were represented in a leisure context. Interestingly, this suggests some independence to chose their own photographs and depict themselves in a more relaxed way:

We had our photographs taken by the guys at Media Resources but we all looked a bit stiff and uniform so I gave them one of me on a camping trip which they put up instead.

(Physicist)

The representation of subjects in muted hues and narrow colour range, one actually in monochrome, helps to realize what Kress and van Leeuwan (1996) regard as 'high modality': cues which impart credibility to the message. On the basis of such modality markers as low colour variation and saturation and the absence of context, the university web designer encourages us to invest the homepage subject with integrity and accept the accompanying text as fact. While unable to control design decisions, however, subjects were able to choose how they faced the camera, and while physicists tended to look serious, most subjects chose to show themselves smiling. The smile invites a connection of social affinity and it is the subject's gaze which dominates, here as in most of these portraits. The academic looks directly at the viewer, bringing about a closer (imaginary) relationship 
between the subject and those who are interested in discovering more about him or her. A contact is established which augments the bare ideational information presented in the accompanying text and perhaps even subverts it by fleshing out the purely professional persona depicted by the institution.

There are, in other words, a range of meanings in these pages, for while the universities seek to enhance their own standing by representing subjects as academics of substance through uniform formality, some individuals exploit what options are available to offer a more personal selfpresentation. The multiplication of meaning and alternative reading paths in these homepages thus offers a complex semantic arena where there may be divergent (and even conflicting) meanings (Liu \& O'Halloran, 2009). In fact, there is no reason to assume a coherent semantic integration of semiotic choices in multimodal spaces and this tension seems to exist here, where individual and institutional purposes interact.

\section{Hyperlinks and connections}

A final aspect of these homepages worth commenting on is the potential interactivity and meanings they establish with the reader through the use of hypertext links. Hypertext is the presentation of information as a linked network of nodes which readers are free to navigate in a non-linear fashion. In webpages it allows for interactivity and multiple reading paths. Just as we make meanings across many paragraphs that we do not make within a single paragraph, so we can make meanings in hypertext through traversals to other sites. Each hypertext link thus provides what Lemke (2002) calls an 'intertextual meaning relation' and in academic homepages these are essentially presentational, tying one topic-specific set of semantic relationships to another. Hyperlink networks seem to offer the reader many potential paths to follow, but choices are actually pre-designed and limited by the page author. For universities this offers opportunities to channel visitors to pages of their choosing, revealing a subject enmeshed in a web of institutional programmes, events, news and so on. For academics, it offers a chance to engage with the reader by indicating social allegiances in a process which Danath and boyd (2004:2) refer to as "public displays of connection". 
Potentially, hyperlinks are key aspects of an online identity construction as they can be seen as flagging topics, stances and people which the author regards as significant (or significantly absent). Turkle (1996: 258) observes that 'one's identity emerges from whom one knows, one's associations and connections', while Miller (1995) puts this more directly: 'Show me what your links are, and I'll tell you what kind of person you are'. Through links to the pages of research groups, labs, friends or departments elsewhere, authors can construct a 'virtual community' (Rheingold 1995). Hyperlinks therefore offer authors an opportunity to individualize their homepage through networks of associations, explicitly claiming membership of particular groups, approval for particular ideas, and relationships with particular others. Unsurprisingly, perhaps, links were overwhelmingly institutional.

The 100 homepages in the corpus contained just under 1400 links, ranging from a handful per page to over 40. The examples in Figures 1 and 2 are fairly typical, both in terms of the frequency of links (Williams containing 20 and Glotzer 27) and in their targets. As can be seen from Table 2, academic homepages represent a complex source- user relationship with a range of implied offers of further information and demands for action (encouraging the user to click to follow a link).

Table 2: Target pages of links on University personal homepages

\begin{tabular}{|l|c|c|c|c|c|c|c|c|}
\hline & University & Dept. & Discipline & Students & Publication & Research & Personal & Totals \\
\hline & & & & & & & & \\
\hline Male & 88 & 296 & 24 & 133 & 134 & 54 & 32 & 761 \\
\hline Female & 86 & 237 & 22 & 123 & 53 & 87 & 25 & 633 \\
\hline & & & & & & & & \\
\hline Physics & 86 & 238 & 11 & 112 & 40 & 116 & 31 & 634 \\
\hline Philosophy & 88 & 295 & 35 & 144 & 147 & 25 & 26 & 760 \\
\hline & & & & & & & & \\
\hline Professor & 86 & 271 & 22 & 136 & 147 & 93 & 32 & 787 \\
\hline Asst Prof & 88 & 262 & 24 & 120 & 40 & 48 & 25 & 607 \\
\hline & & & & & & & & \\
\hline Total links & 174 & 533 & 46 & 256 & 187 & 141 & 57 & 1394 \\
\hline Percent links & 12.5 & 38.2 & 4.1 & 18.4 & 12.6 & 10.1 & 4.1 & 100 \\
\hline Total authors & 100 & 99 & 29 & 86 & 28 & 69 & 55 & \\
\hline
\end{tabular}

Departmental information dominates the frequencies and together with links to university pages, these connections to the staff, facilities, events, alumni and research comprise half of all the links in the 
corpus. Information about and for students is the next most common link and occurs on all but 6 homepages in the sample. Institutional links therefore overwhelm those of the subject.

Links associated directly with the identity of the authors themselves, relating to their publications and conferences, their research, and their personal interests, not only largely served to discursively construct academics in the university's image, but comprised just $27 \%$ of all hyperlinks. Disciplinary links, which take readers to affiliated labs and centres elsewhere, journal websites, professional associations, and so on, serve both personal and institutional interests and comprise $4 \%$ of links. We can, however, observe a distinction in the university and individual connections, for while the institutional links might be seen as a directory of further information, author links are the equivalent of verbal invitations, encouraging the viewer to discover more about the individual. This type of author-user relationship in hypertext gives rise to a sense of interactive dialogue, allowing the author the opportunity to escape monologism by creating a pseudo-dialogue with the user.

We can also see mediating factors in individual choices which suggest that there is some control by individuals in the selection of these links. Table 2 shows that the categories of links do not always correspond with the content categories discussed above. Males, professors, and philosophers all created substantially more links and these were mainly to their departments, students and publications. Professors, unsurprisingly, linked almost four times more to their publications, for example, and males provided one and a half times more links to their publications; females, in contrast, directed readers to their research. Those mentioning research, however, were about three times more numerous for both gender groups and the high figures for publication links can be accounted for by the reporting practices of some dozen senior male philosophers averaging about 12 or 13 links each.

While similar numbers of individuals in each discipline posted links in each of the categories, philosophers used more hyperlinks in almost all of them except research. Virtually all physicists had 
links to their research interests or, more often, also to their research group, with five times more links. These examples are typical (links underlined):

(9) Research activities

$\mathrm{KTeV}$ Experiment at Fermilab, KTeV: University of Chicago

Braidwood Experiment: Reactor Neutrino Measurement of Theta_13

APS Neutrino Study: Reactor Working Group

The 1st phase of the XENON program is well underway, with a $10 \mathrm{~kg}$ TPC (XENON10) currently operating underground at the Italian Gran Sasso Laboratory (LNGS). The detector, built at Nevis Labs, was moved in March 2006 and it has been running continuously and stably for the past five months in dark matter search mode. First results from this experiment are expected by Spring 2007. The Picture Gallery has a selection of images on the XENON10 experiment.

Interestingly, some physicists saw this as an opportunity not only to a present a representation of themselves through the labs and groups they were associated with, but to promote their fields of interests to outsiders and non-specialists. In the corpus of physics homepages, links are often to sites for the public or online encyclopaedia:

(10) Our group is a member of the Compact Muon Solenoid (CMS) experiment, which has constructed a massive detector for the Large Hadron Collider (LHC). The LHC is a $14 \mathrm{TeV}$ proton-proton colliding beam accelerator, which has been constructed at the European accelerator center, CERN, in Geneva, Switzerland. To find out more, visit the CMS web page and CERN's web page.

\section{Research Interests}

* Quantum Information Science <http://en.wikipedia.org/wiki/Quantum_information_science>

* Entanglement <http://en.wikipedia.org/wiki/Quantum_entanglement>

* Quantum Optics <http://en.wikipedia.org/wiki/Quantum_optics>

Links therefore seem to be less amenable to the university's editorial control than content. But while 55 academics linked their page to a 'personal' target such as a curriculum vitae, few linked to a nonacademic site. 53 individuals, however, chose to link to personal site. Calling the visitor to a personal homepage enables the author to reclaim some control over format, layout, links and content and, if he or she chooses, to represent a more rounded identity as someone with a life outside the academy. 
These opportunities, however, were seldom taken and while the appearance of the pages differed from the university pages, the content - and the links - often remained much the same.

As I noted when discussing the moves of these homepages, academic material predominated on the personal pages and this was also true of the targets of their links. Just $7 \%$ of the links on the personally-constructed pages referred to more private aspects of the self such as family pictures, hobbies, interests, or other icons (see example 5 above). More usually, links followed similar patterns to those on the university pages (again, underlining indicates links):

(11) W E L C O M E and thank you for visiting my website.

I am a University Lecturer in the Faculty of Philosophy at the University of Cambridge, and a Fellow in Philosophy at Jesus College, Cambridge.

My field is contemporary political philosophy. I am particularly interested in:

1. contemporary liberalism, including autonomy, equality, multiculturalism and global justice;

2. feminism, including the body, appearance norms and personal relationships;

3. theories of social construction, including those of Michel Foucault and Pierre Bourdieu.

On these pages you will find more information on my research, publications and teaching.

Clearly, people who create their own homepage want to present a certain version of themselves to the world, or at least that part of the world interested enough to search for them, and links to others can help this creation. Who we publicly wish to be associated speaks of how we want to be seen, the communities we belong to, the interests we have and the people we value. It seems, however, that even when freed from institutional constraints, these academics rarely stray beyond links to information related to an academic persona.

\section{Conclusions}

Critics complain that personal home pages are often trivial, amateurish and superfluous products of narcissism and exhibitionism, where "assertive confession" and endless lists predominate (Rothstein, 1996) while advocates stress the emancipatory and self-reflexive potential of autonomous portrayals 
of individuals in a public space. Academic homepages seem to fall outside of these generalisations and perhaps only peripherally qualify as homepages in the sense which it is normally used. Certainly these pages promote the individual academic and their accomplishments, but equally they discursively construct the individual as a member of an institution which profits from these accomplishments. Clearly, universities have different policies and different tolerances of deviance while different academics will have different responses to institutional control. It is therefore difficult to make generalisations, but homepages are of interest to EAP practitioners, I believe, and their study can contribute to theory building, language understanding, and pedagogy.

First, the analysis of homepages offers insights into the working of an important, and previously under-investigated genre, revealing the workings of language and how it interacts with other semiotic resources for particular social purposes. In what is included and the ways it is assembled the homepage reveals the negotiation of impression management within specific relations of power. The content of personal home pages, whether the text, design, visuals or links, draws on a palette of conventional paradigmatic elements which not only make information about subjects accessible to a potential world-wide audience, but which promote a version them and their university to that audience. The fact that we find mainly professional biographies and references to research interests and publications; that the design reveals the uniform repetition of a university brand; that the visuals are restricted to cropped passport style portraits; and that links largely take us to places which reinforce the competent, accomplished academic, all reveal a genre which enhances the status of the author and subjugates him or her to its homogeneity.

Second, studying homepages adds to our understanding of identity, its construction in academic contexts, and the ways that factors such as discipline, rank and gender potentially impact on this construction in the face of institutional pressures towards conformity. Community Discourses, and their social ideologies, assist the performance of identities by providing broad templates for how people see and talk about the world and about themselves. Our identities draw heavily on these schema as they both shape and enable particular versions of who we are and how we want to be 
regarded by those whose opinions we value. In an important sense, identity means constructing credibility, it involves negotiating a self which is coherent and meaningful to both the individual actor and the group. In the ways individuals seek to achieve specific promotional goals through the presentation of themselves in homepages, then, writers are also managing a considered and rhetorically machined identity likely to appear credible to others.

In these constructions of online identities we find something of the perceptions and values of academic communities as writers assemble a persona which draws on insider perceptions of what their disciplines find meaningful and important. We also, however, see something of the tensions, compromises and negotiations in this enactment of an online self. The authors in this sample were largely complicit in what can appear to be attempts by universities to marginalize faculty members as simply institutional functionaries. Turning to personal homepages situated outside direct departmental governance, we find a more multifaceted self, but this still places a professional expertise at the centre. The individual's attachment to a particular position and his or her commitment to perform a role as an academic clearly serves as the most powerful platform for all their other facets.

Finally, the study of homepages might have pedagogical value in describing a genre useful to students and professionals. This is a self-promotional as much as an informational genre and by creating such pages, academics can, within limits, strategically manage something of their selfpresentations. A better understanding of the workings of this genre might assist individuals to reclaim a personal subjectivity from the juggernaut of institutional branding and further their careers by presenting themselves in the most effective way. Perhaps more importantly, however, the process of constructing a homepage can itself be a valuable experience. It encourages individuals to think about which aspects of their identity should be presented and how language works in combination with other modalities, so promoting both genre awareness and a better understanding of the relationship between texts and achieving social purposes. 
This has been a relatively small-scale study of 100 homepages and three main variables and there is, of course, more work to be done in this area. It would, for example, be interesting to look at other disciplines, to interview more authors on their writing decisions and readers on the impact of those decisions. It is also worth exploring non-university pages more extensively than the 50 or so examined briefly here to see how authors subvert or conform to institutional requirements, or to examine more thoroughly the impact of national academic cultures on the bricolage of academic homepages. I hope, however, to have established an agenda for this research and to have shown that the personal homepage has to be recognized as a rich set of options for portraying an academic self.

\section{References}

Adler, E., Gent, C.E. \& Overmeyer, C. (1998). The home style homepage: legislator use of the world wide web for constituency contact. Legislative Studies Quarterly,. 23,. 4, pp. 585-595

Arnold, J. \& Miller, H. (2001). Breaking away from grounded identity? Cyberculture and gendered acadmic identities on the web. Paper presented at Constructing cyberculture(s): Performance, pedagogy and politics in online spaces, College Park, MD.

Benwell, B. \& Stokoe, E. (2006). Discourse and identity. Edinburgh: Edinburgh University Press.

Bonnardel, N., Piolat, A. \& Le Bigot, L. (2010). The impact of colour on website appeal and users' cognitive processes, Displays doi: 10.1016/j.displa.2010.12.002

Chandler, D. (1998). Personal homepages and the construction of identities on the web. Paper presented at Aberystwyth Post-International Group Conference on Linking theory and practice: issues in the politics of identity, 9-11 Sept. 1998. University of Wales. http://www.aber.ac.uk/media/Documents/short/webident.html

Chandler, D. \& Roberts-Young, D. (1998). The construction of identity in the personal homepages of adolescents. http://www.aber.ac.uk/media/Documents/short/strasbourg.html

Danath, J. \& Boyd, B. (2004). Public displays of connection. BT Technology Journal, 22 (4) 1-11.

Dumont, K. \& Frindte, W. (2005). Content analysis of the homepages of academic psychologists. 
Computers in Human Behavior 21, 1: 73-83

Foucault, M. (1972). The archeology of knowledge. London: Tavistock.

Gergen, K. (1991). The saturated self: dilemmas of identity in contemporary life. New York: Basic Books.

Giddens, A. (1991). Modernity and self-identity.: self and society in the late modern age. Cambridge: Polity Press.

Goffman, E. (1971) The presentation of self in everyday life. Harmondsworth: Penguin Books.

Hess, M. (2002). A nomad faculty: English professors negotiate self-representation in university web space. Computers and composition. 19 (2): 171-189.

Hyland, K. (2011). Projecting an academic identity in some reflective genres. Iberica. 21: 9-30.

Hyland, K. \& Tse, P. (forthcoming). 'She has received many honours': Identity in Article Bio Statements.

Ivanic, R. (1998). Writing and identity: The discoursal construction of identity in academic writing, Amsterdam: John Benjamins.

Jewitt, C. (2005), 'Multimodality, reading, and writing for the 21st century', Discourse: Studies in the Cultural Politics of Education, 26, 315-31.

Kraus, W. (2000). Making identity talk. On qualitative methods in a longitudinal study. FQS 1, 2. http://www.qualitative-research.net/index.php/fqs/article/view/1084

Kress, G. (2010), Multimodality: A social semiotic approach to contemporary communication. London: Routledge.

Kress, G. \& van Leuwen, L. (1996). Reading images: the grammar of visual design. London: Routledge.

Lemke, J. L. (2002), Travels in hypermodality, Visual Communication, 1, 299-325.

Lillis, T. (2001). Student writing. London: Routledge.

Liu, Y., and O'Halloran, K. L. (2009), 'Intersemiotic texture: Analyzing cohesive devices between language and images', Social Semiotics, 19(4), 367-387.

Liu, C., Arnett"K. , Capella, L. \& Beatty, R. (1997). Web sites of the Fortune 500 companies: Facing customers through home pages. Information \& Management, 31, 6, 335-345 
Miller, H. (1995). The presentation of self in electronic life: Goffman on the internet. Retrieved 1 April, 2010 from http://www.docstoc.com/docs/2168575/The-Presentation-of-Self-inElectronic-Life-Goffman-on-the-Internet/

Parks, M. \& Archley-Landas, T. (2003). Communicating self through personal homepages: is identity more than screen deep? Paper presented at the Annual Conference of the International Communication Association, San Diego, CA.

Rheingold, H. (1995). The virtual community: finding connection in a computerized world. London: Minerva.

Stern, S.R. (2004). Expressions of identity online: Prominent features and gender differences in adolescents' world wide web home pages. Journal of Broadcasting \& Electronic Media, 48, 2: $218-243$

Tang, J., Zhang, D. Yao, L. (2007). Social network extraction of academic researchers. Seventh IEEE International Conference on Data Mining. pp.292-301,

Tang, L. (2007). Coping with separation Chinese seafarer-partners in cyberspace. University of Cardiff unpublished PhD thesis. http://www.sirc.cf.ac.uk/Nippon\%20Fellows/Theses/Tang.pdf Tannen D. (1990). You just don't understand: women and men in conversation. New York: Ballantine, Thoms, L. \& Thelwall, M. (2005) . Academic home pages: reconstruction of the self. First Monday . 10(12), http://www.firstmonday.org/issues/issue10_12/thoms/

Tse, P. \& Hyland, K. (2009) Discipline and Gender: Constructing Rhetorical Identity in Book Reviews. In Hyland, K. \& Diani, G. (Eds). Academic evaluation: review genres in university settings. London: Palgrave-MacMillan. pp 105-121.

Turkle, S. (1996): Life on the screen: identity in the age of the internet. London: Weidenfeld \& Nicolson

Wynn, E., \& Katz, J. E. (1997). Hyperbole over cyberspace: Self-presentation and social boundaries in internet home pages and discourse. The Information Society, 13(4), 297-328.

\section{Notes}

${ }^{\mathrm{i}}$ http://www.topuniversities.com/university-rankings/world-university-rankings/2009/results 